which alone is as large as many an atoll, is thus shown not to be underlaid by an abraded platform, there is no sufficient reason for thinking that the southern compartment, or indeed any other barrier reef or atoll lagoon in the whole Pacific, has any such smoothly prepared foundation. Surely if the flatness of the floor and its normal depth in both compartments of the Tagula lagoon have been brought about in a region of instability, and without the aid of abrasion in furnishing a smooth sub-lagoon platform, there is no sufficient reason for assuming that other flat lagoon floors of ordinary depth can have been prepared only on smooth platforms abraded at a standard depth across still-standing islands. It is possible that the Glacial lowering of the ocean surface by a moderate amount may have contributed, in a manner that I have suggested elsewhere, ${ }^{5}$ to the production of many lagoon floors 30 or 40 fathoms in depth; but Glacial changes of ocean level do not seem otherwise to have left recognisable marks of their occurrence in the Louisiade archipelago. Crustal deformation has been dominant; and the great changes of shore lines thus determined appear to have been merely played upon by the inferred oscillations of ocean level during the Glacial period.

This discussion is believed to show that, apart from such changes of ocean level as are inherently probable although they are not well-known either in amount or in effects, the assumptions of the Glacialcontrol theory are not applicable in the production of Tagula reef and lagoon floor; and hence we may fairly conclude that these assumptions are not essential to the production of similar reefs and lagoon floors elsewhere. This argument, in which the evidence furnished by one outspoken witness for

5 " Problems associated with the Study of Coral Reef," Sci. Monthly, 2, I9I6 (565).
Darwin's theory and against the Glacial-control theory is given wide application, would not be valid if other witnesses were equally outspoken elsewhere against Darwin's theory and for the Glacial-control theory; but such is not the case. It must be remembered that the two main postulates of the Glacial - control theory, namely, long - continued stability of reef foundations in the mid-Pacific and the abrasion of sub-lagoon platforms by the lowered Glacial ocean, are not based on direct evidence but are assumed because they are supposed to be necessary for the explanation of smooth lagoon floors of standard depths. Not a single example of an abraded platform has been discovered under recently uplifted reefs; and a large number of mid-Pacific islands which have a decipherable recent history are found not to have been long stable but to have suffered various changes of level. In other words, where other outspoken witnesses are found, their testimony is, like that of Tagula, for Darwin's theory of upgrowing reefs on subsiding foundations of whatever shape. A large number of examples of this kind could be adduced if space permitted.

But although the inhibition of reef growth and the resulting abrasion of low-level platforms by the Glacial ocean thus appear to be excluded from the greater part of the coral seas, it is highly probable that reef-building organisms may have been weakened or killed and that abrasion of platforms may have taken place around islands near the margin of the coral seas; and at least some of those islands ought now to show plunging cliffs in evidence of their possession of submerged platforms; but even there the islands need not have been stable. This aspect of the coral-reef problem is examined in an essay submitted to the Geological Society of America for publication in its Bulletin.

\title{
Root Respiration. ${ }^{1}$
}

\section{A}

LTHOUGH so much work has been done on the question of root respiration, it is only within the last few years that the importance of the air content of the soil in this connexion has been clearly demonstrated. With the growth of ecological work has come the indication that this air content is a primary factor in many habitats and a controlling one in wet soil and water, but even yet this is not generally recognised.

Mr. F. E. Clements has endeavoured to clear the ground for further research in this direction by summarising the available information in all its aspects. From the time of Mayou (r668) the necessity of oxygen for root activity has been recognised, and numerous investigations have since added to the bulk of evidence with studies of germination, anaerobic respiration, and the respiratory behaviour of underground parts other than roots. The excretion of carbon-dioxide by the roots was first noted by Hales ( 1727 ), but the possible excretion of other substances is still a matter of controversy at the present day. Molisch first showed that roots exhibit the phenomenon of aerotropism or response to different concentrations of various gases. This is of great significance in plants inhabiting bogs and swampy land, as in order to obtain the oxygen necessary for respiration they develop aerotropic roots which run horizontally above the oxygen-free swamp soil, as in Alnus, or rise vertically in the air, as in Avicennia.

The composition of the soil air varies considerably with the nature of the soil, time of year, and seasonal

1 "Aeration and Air Content: the Rôle of Oxygen in Root Activity," by Frederic E. Clements. Pp. 183. (Publication 315.) (Washington: Carnegie" Institution, rg2r.) 2 dollars. changes, and is also affected by cultivation and plant growth, which increase the carbon-dioxide and diminish the oxygen in proportion. It has been suggested by Bristol that the presence of algæ may also affect the soil gases.

Anaerobic respiration is of much significance in connexion with reduced oxygen supply. The general effect of the reduction or absence of oxygen on respiration is to reduce its intensity, but respiration under anaerobic conditions differs with the species. Carbondioxide and alcohol are the regular products of such respiration, which is consequently regarded by most investigators as essentially identical with alcoholic fermentation when carbohydrates are present. Under certain conditions acetic, formic, and lactic acids are excreted from the roots and other parts of flowering plants. After considering the relation of photosynthesis, transpiration, and germination to oxygen supply, Mr. Clements enunciates the general rule that growth is decreased or prevented by the absence of oxygen. The movement of protoplasm in plant cells is stopped, and practically all tropistic responses are suppressed.

Field studies of aeration, approached from the agricultural, pathological, and ecological standpoints, corroborate the results of physiological investigation as to the basic importance of oxygen for root activity and the injury wrought by the accumulation of carbon-dioxide. The practical importance of this appears most strikingly in irrigated regions where the common practice involves the use of too much water, with consequent economic loss, due to the production of an oxygen deficit in the soil. 
The problem of soil aeration and the way in which it works injury to plants is much under discussion, but it appears certain that in some soils the lack of oxygen and the accumulation of carbon-dioxide are primary factors, while the organic acids and salts arising from anærobiosis may play some part. In other cases acidity brings salts of aluminium, iron, or manganese into solution, which then exert a toxic effect.

Finally, after putting forward the present position of affairs with regard to toxic exudates and soil toxins, the author concludes his valuable survey with a comprehensive bibliography which contains more than seven hundred references. W. E. B.

\section{Radio Direction Finding in Flying Machines.}

THERE is little doubt that radio direction finders and other radio devices will soon be in regular use to enable aeroplanes to land at night, during fogs or at other times of poor visibility. The usual method is to transmit signals from an antenna in the landing field to the direction-finder on the aeroplane. This, however, gives merely the direction of the landing-field and provides no indication to the navigator of his distance from his destination.

Some years ago the Bureau of Standards in America experimented with induction signalling. A large horizontal single turn coil, 600 by 800 feet, was erected at the landing-stage. It was tuned to resonance at a frequency of 500 so that it produced a very powerful alternating magnetic field over a wide area in the neighbourhood. It was found that induction effects could be detected at considerable distances when the aeroplane was at a low altitude, but at the height of a mile they could be detected only throughout a small area directly over the coil. The tests showed that what was wanted was a hollow conical beam of radiation, the vertex of the beam being on the landing ground. At low altitudes it was very important that the signal should be audible over only a very limited range.
This has been effected by means of two equal coaxial coils with their planes horizontal and at different altitudes. The current, which has a radiofrequency of 300,000 , flows in opposite directions in the two coils. Under these conditions the signals are received at the aeroplane only when the machine is in the immediate neighbourhood and approaching or receding from the station.

Gregory Breit, a physicist of the Bureau of Standards, has worked out mathematically the nature of the field from the two horizontal coils. It is proved that the maximum intensity of the signals occurs when the angle which the line joining theaeroplane with the landing-stage makes with the vertical is approximately $30^{\circ}$. The region of space within which the signal can be detected is nearly the space between two inverted coaxial cones with their axes vertical and their common apex at the transmitting station. The signals are inaudible directly overhead and rapidly die away when the aeroplane passes through the conical surface where the sound is a maximum. The lower the aeroplane also the louder the noise. The theoretical results have proved of great value in designing stations for emitting landing signals, and should be of considerable practical importance.

\section{Industrial Research in India.}

$\mathrm{O}^{\mathrm{N}}$ $\mathrm{E}$ of the bye-products of the new constitution legalised by the Government of India Act of I9I9 was the transfer of certain " heads of business," previously administered by the bureaucratic regime, to the control of popularly elected Ministers in each province. The subjects. so transferred included agriculture, forests, and the development of industries, with, therefore, the scientific and technical services attached to these departments, Realising that " decentralisation of authority and responsibility must necessarily tend to give rise to local variations in policy, apart altogether from those variations that follow local diversity in natural resources," Sir Thomas Holland, when designing the new Department of Industries and Labour in I920, elaborated a system which would facilitate concerted action among the provinces while leaving them free to develop in any way that seemed to their respective legislatures best suited to their special needs. The new Ministers were, in the first instance, provided with a monthly circular summarising the information, often of a semi-confidential nature, collected by the Intelligence Branch of the Munitions Board. Out of these circulars grew the agenda of half-yearly conferences, followed by a quarterly Journal and a series of Bulletins suitable for publication.

During I92I four parts of the first volume of the Journal, amounting to 568 pages, well illustrated and fully indexed, were issued, and we have now received the first part of the new volume for I922, together with twenty-three Bulletins on special subjects. The first part of the Journal published in $192 \mathrm{x}$ was noticed last year in NATURE of April 7 (vol. I07, p. I79), and it is satisfactory to observe that the quality of the papers and the fundamental object of the publication have both been faithfully maintained.
Some of the articles, like those by Dr. E. R. Watson and Mr. Mukerji on the alkaline "bad lands " of the United Provinces, by Mr. B. M. Das on the tan-stuffs of the mangrove swamps on the Gangetic delta, by Mr. Appleyard on the manufacture of acetone and butyl alcohol, and by Messrs. Gadre and Mukerji on rose otto, include the results of original research; but generally the articles and notes have an industria rather than a scientific bias, avoiding the ground covered by those scientific and technical departments that have established journals of their own. Problems of factory welfare, which are beginning to assume embarrassing importance in India, occupy a conspicuous place among papers describing local ventures in glass manufacture, paper-making, tanning, pottery, oil-extraction, perfume distillation, wiredrawing, textile manufacture, and mineral enterprises.

The progress reports provided quarterly by the provincial Directors of Industries show the efforts being made to carry out the recommendations of the Industrial Commission which delivered its report towards the end of 1918 . The reports generally give some justification for the claim made by Lord Chelmsford in his article in the United Empive for December last (vol. xii. p. 778 ) that " never has effect been given more expeditiously" to a Commission's report. Differences of provincial outlook, however, still retard the adoption of the excellent scheme of chemical research drawn up by Prof. Thorpe's Committee in I920; and without some such organisation to this end, by co-operation among the provinces, the industries of India must always retain their primitive " configuration" and remain distinctly behind, for example, those of a country like Japan. 